\title{
Differential HMG-CoA lyase expression in human tissues provides clues about 3-hydroxy-3-methylglutaric aciduria
}

\author{
Beatriz Puisac • María Arnedo • Cesar H. Casale • María Pilar Ribate • \\ Tomás Castiella • Feliciano J. Ramos • Antonia Ribes • Celia Pérez-Cerdá • \\ Nuria Casals • Fausto G. Hegardt • Juan Pié
}

Received: 29 December 2009/Revised: 30 March 2010/Accepted: 1 April 2010 /Published online: 8 June 2010

(C) The Author(s) 2010

\begin{abstract}
Hydroxy-3-methylglutaric aciduria is a rare human autosomal recessive disorder caused by deficiency of 3-hydroxy-3-methylglutaryl CoA lyase (HL). This mitochondrial enzyme catalyzes the common final step of leucine degradation and ketogenesis. Acute symptoms include vomiting, seizures and lethargy, accompanied by metabolic acidosis and hypoketotic hypoglycaemia. Such organs as the liver, brain, pancreas, and heart can also be involved. However, the pathophysiology of this disease is only partially understood. We measured mRNA levels, protein expression and enzyme activity of human HMGCoA lyase from liver, kidney, pancreas, testis, heart,
\end{abstract}

Communicated by: K. Michael Gibson

Competing interest: None declared.

B. Puisac $\cdot$ M. Arnedo $\cdot$ M. P. Ribate $\cdot$ F. J. Ramos $\cdot$ J. Pié $(\square)$ Laboratory of Clinical Genetics and Functional Genomics,

Department of Pharmacology and Physiology,

School of Medicine, University of Zaragoza,

C/ Domingo Miral s/n,

50009 Zaragoza, Spain

e-mail: juanpie@unizar.es

C. H. Casale

Department of Molecular Biology,

National University of Rio Cuarto,

5800 Rio Cuarto, Cordoba, Argentina

T. Castiella

Department of Pathology, School of Medicine,

University of Zaragoza,

50009 Zaragoza, Spain

\section{A. Ribes}

Division of Inborn Errors of Metabolism (IBC),

Department of Biochemistry and Molecular Genetics,

Hospital Clinic and CIBERER,

08036 Barcelona, Spain skeletal muscle, and brain. Surprisingly, the pancreas is, after the liver, the tissue with most HL activity. However, in heart and adult brain, HL activity was not detected in the mitochondrial fraction. These findings contribute to our understanding of the enzyme function and the consequences of its deficiency and suggest the need for assessment of pancreatic damage in these patients.

\section{Abbreviations \\ HMG-CoA 3-hydroxy-3-methylglutaryl CoA \\ HL HMG-CoA lyase}

\section{Pérez-Cerdá}

Department of Molecular Biology,

Molecular Biological Center Severo Ochoa CSIC-UAM,

University Autonoma of Madrid, CIBERER,

28049 Madrid, Spain

N. Casals

Department of Biochemistry and Molecular Biology,

School of Health Sciences,

International University of Catalonia,

08190 Sant Cugat, Barcelona, Spain

\section{F. G. Hegardt}

Department of Biochemistry and Molecular Biology,

School of Pharmacy, University of Barcelona,

08028 Barcelona, Spain

N. Casals $\cdot$ F. G. Hegardt

CIBER Fisiopatología de la Obesidad y Nutrición (CIBEROBN),

Instituto de la Salud Carlos III,

28029 Madrid, Spain 


\section{Introduction}

3-Hydroxy-3-methylglutaric aciduria (MIM 246450) is a rare human autosomal recessive disorder caused by deficiency of 3-hydroxy-3-methylglutaryl CoA lyase (HMG-CoA lyase, HL, EC 4.1.3.4) (Faull et al. 1976). This mitochondrial enzyme catalyzes the cleavage of HMG-CoA to form acetyl-CoA and acetoacetate, which is the common final step in leucine degradation and ketogenesis.

The disease usually appears in the first year of life after a fasting period or during intercurrent illness. Acute symptoms include vomiting, seizures and lethargy, accompanied by metabolic acidosis, hypoketotic hypoglycaemia and a characteristic pattern of elevated urinary organic acid metabolites (Gibson et al. 1988; Schutgens et al. 1979; Wysocki and Hahnel 1986). Such organs as the liver and brain are frequently affected, and occasionally the pancreas and heart can also be involved (Gibson et al. 1994; Leung et al. 2009; Muroi et al. 2000; Urganci et al. 2001; Wilson et al. 1984; Zafeiriou et al. 2007; Zoghbi et al. 1986).

The pathophysiology of this disease is only partially understood. It may be explained by the deficit of an alternative energy source (ketone bodies), the intracellular accumulation of toxic organic acids or fatty acids or secondary carnitine deficiency (Kahler et al. 1994; Mitchell et al. 1995; Leung et al. 2009). However, these interpretations were not based on a thorough understanding of the expression or activity of HL in the affected tissues. To our knowledge, HL has been examined only in liver, leukocytes and fibroblasts (Ashmarina et al. 1994; Wysocki and Hahnel 1976a; Wysocki and Hahnel 1976b) but not in other human tissues. This report is the first study of mRNA levels, protein expression and enzyme activity of human HMG-CoA lyase in kidney, pancreas, testis, heart, skeletal muscle, and brain. The results may improve our understanding of the enzyme function and the involvement of these organs in 3-hydroxy-3-methylglutaric aciduria.

\section{Materials and methods}

HL mRNA

HL mRNA was measured in Multiple Tissue cDNA (MTC) panels (Clontech) by a Real-Time quantitative PCR method using a TaqMan Gene Expression Assay (Assay HMGCL: Hs00609306_m1 Assay GAPDH:Hs99999905_m1) (Applied Biosystems). The levels of HL mRNA was calculated relative to the $G A P D H$ control by the $\triangle \triangle \mathrm{Ct}$ method. The level of expression HL in skeletal muscle was arbitrarily taken as the calibrator to normalize the other tissues.
HL protein analysis

Human tissues: liver, kidney, pancreas, testis, heart, skeletal muscle, and brain were obtained within $10-12 \mathrm{~h}$ post mortem at autopsy from two male subjects at the Department of Pathology of our University. They were 65 and 70 years old, and representative samples of organs of approximately $1-2 \mathrm{~g}$ were taken from each subject. To minimize protein degradation, the bodies were kept at $4^{\circ} \mathrm{C}$ until autopsy and all the tissues were immediately shockfrozen in $\mathrm{N} 2$ and stored at $-80^{\circ} \mathrm{C}$ until use.

To isolate the mitochondrial fraction from human tissues, we performed subcellular separation as described by Clinkenbeard et al. (1975). Mitochondrial proteins separated on a $15 \%$ SDS-PAGE were transferred to a $0.45-\mu \mathrm{M}$ nitrocellulose membrane by transfer blot. The membranes were probed with a mouse monoclonal antibody against $\mathrm{HL}$ (Abnova) (1:1,000 dilution) and revealed with the kit SuperSignal West Dura Extended Duration substrate (Thermo Scientific) using a peroxidase-conjugated secondary anti-mouse antibody (Sigma, 1:1,000). The protein bands were quantified using Scion ImageJ v1.39u software (Scion) and normalized to micrograms of total protein obtained from $10 \mathrm{mg}$ of tissue. The density of the band corresponding to the liver was taken as $100 \%$.

HL activity

After subcellular separation, $20 \mu \mathrm{l}$ of mitochondrial fraction of different tissues (about $200 \mu \mathrm{g}$ of protein) was used to measure enzymatic activity. HMG-CoA lyase activity was assayed by the spectrophotometric assay described by Wanders et al. (1988), which measures the amounts of acetoacetate produced. The level of activity was expressed as $\mathrm{mU} / \mathrm{g}$ wet weight tissue (one milliunit equals $1 \mathrm{nmol}$ of substrate converted/min).

\section{PAP measurements}

Serum samples were collected in acute and inter-crisis periods from 15 patients with 3-hydroxy-3-methylglutaric aciduria and stored at $-20^{\circ} \mathrm{C}$. All patients were diagnosed biochemically, and most of them were also diagnosed genetically (Table 1). Human serum PAP (pancreatitis associated protein) concentration was determined in control and patients by a kit based on a sandwich immunoenzymatic system (PancrePAP, Dynabio).

\section{Results}

HL mRNA was detected in all the tissues studied, albeit in widely differing amounts. Tissues with the highest expres- 
Table 1 Diagnostic parameters and pancreatitis associated protein (PAP) measurements in patients with 3-hydroxy-3methylglutaric aciduria

PAP values in controls $(17.46 \pm$

$8.27 \mathrm{ng} / \mathrm{ml}$, mean $\pm \mathrm{SD}, \mathrm{n}=11$ )

+ Elevated organic acids

(3-hydroxy-3-methylglutaric,

3-methylglutaconic,

3-methylglutaric and

3-hydroxy-isovaleric); — no

data; PAP values measured

in periods intercrisis and

${ }^{\mathrm{a}}$ in acute crisis. PAP values $<$

$50 \mathrm{ng} / \mathrm{mL}$ are considered normal

\begin{tabular}{|c|c|c|c|c|}
\hline Case & Organic acids & $H M G C L$ mutation & PAP (ng/mL) & Reference \\
\hline $\mathrm{P} 1$ & + & c. $109 \mathrm{G}>\mathrm{T}$ & 6.72 & Casale et al. 1998 \\
\hline $\mathrm{P} 2$ & + & c. $109 \mathrm{G}>\mathrm{T}$ & 8.49 & Casale et al. 1998 \\
\hline P3 & + & c.109G $>$ T/c504_5delCT & $\begin{array}{l}20.12^{\mathrm{a}} \\
31.87\end{array}$ & Menao et al. 2009 \\
\hline P4 & + & c. $144 \mathrm{G}>\mathrm{T} / \mathrm{c} .504 \_5 \mathrm{delCT}$ & 5.61 & Menao et al. 2009 \\
\hline P5 & + & c.202_207delCT & 9.42 & Menao et al. 2009 \\
\hline P6 & + & c. $575 \mathrm{~T}>\mathrm{C}$ & 6.17 & Menao et al. 2009 \\
\hline $\mathrm{P} 7$ & + & c. $109 \mathrm{G}>\mathrm{T}$ & 5.39 & Menao et al. 2009 \\
\hline P8 & + & c. $109 \mathrm{G}>\mathrm{T}$ & 7.85 & Menao et al. 2009 \\
\hline P9 & + & c. $109 \mathrm{G}>\mathrm{T} / \mathrm{c} .825 \mathrm{C}>\mathrm{G}$ & $\begin{array}{l}5.80^{\mathrm{a}} \\
7.37\end{array}$ & $\longrightarrow$ \\
\hline $\mathrm{P} 10$ & + & c. $109 \mathrm{G}>\mathrm{T}$ & $2.13^{\mathrm{a}}$ & Menao et al. 2009 \\
\hline $\mathrm{P} 11$ & + & c. $109 \mathrm{G}>\mathrm{T} / \mathrm{c} .504 \_5 \mathrm{delCT}$ & $5.35^{\mathrm{a}}$ & $\longrightarrow$ \\
\hline $\mathrm{P} 12$ & + & c. $242 \mathrm{G}>\mathrm{A}$ & $5.93^{\mathrm{a}}$ & - \\
\hline $\mathrm{P} 13$ & + & - & 13.63 & $\longrightarrow$ \\
\hline $\mathrm{P} 14$ & + & $\longrightarrow$ & $\begin{array}{l}26.92^{\mathrm{a}} \\
10.46\end{array}$ & - \\
\hline P15 & + & $\longrightarrow$ & 6.16 & $\longrightarrow$ \\
\hline
\end{tabular}

sion or controversial ketogenic capacity are reported in Fig.1a: [liver 112.2 arbitrary units (100\%) pancreas 43.5 (39\%), kidney $17.56(16 \%)$, testis $26.81(24 \%)$, heart 2.96 $(2,6 \%)$, brain $2.26(2 \%)$, and skeletal muscle $1(0.89 \%)]$. The highest protein levels were found in human liver $(100 \%)$, followed by pancreas $(89 \%)$, testis $(60 \%)$, kidney $(42 \%)$, and skeletal muscle (36\%); a weak signal was detected in heart (2\%) and brain (1.8\%) (Fig 1b). The enzyme activity was measured in the mitochondrial fraction. The liver had the highest activity $(128.86 \mathrm{mU} / \mathrm{g}$ of wet weight tissue, $100 \%$ ), followed by pancreas (58.49 mU/g, 45\%), kidney (42.48 mU/g, 33\%), testis $(20.23 \mathrm{mU} / \mathrm{g}, 16 \%)$, and skeletal muscle $(12.6 \mathrm{mU} / \mathrm{g}$, $9,7 \%$ ). HL enzyme activity was not detected in heart or brain (Fig. 1c).

The values of PAP in patients varied between 5.31$31.87 \mathrm{ng} / \mathrm{mL}$ (Table 1) within a normal range $(<50 \mathrm{ng} / \mathrm{mL}$ ) (Desjeux et al. 2002). Simultaneously, we also measured PAP protein in 11 normal subjects as controls, and no differences (range $6.12-32.61 \mathrm{ng} / \mathrm{mL}$ ) were found.

\section{Discussion}

This is the first time that a complete study of mRNA, protein and enzymatic activity of HL has been reported in a broad range of human tissues. The findings on the expression level and enzymatic activity of HL in these tissues may help us to understand the pathophysiology of HL deficiency.

Our results show that the liver has the highest HL activity, followed by pancreas. Both organs showed high levels of mRNA, protein and HL enzyme activity. The liver is the organ most frequently affected in this deficiency, although involvement is usually mild, with elevated transaminases and hepatomegaly (Urganci et al. 2001; Wysocki and Hahnel 1986). Since the liver does not use ketone bodies as a source of energy (Robinson and Williamson 1980), its deficit is not the cause of the disease. However, ketogenesis is more active in the liver and the blockage of this pathway could result in an accumulation of toxic intermediate metabolites. Recently, Leipnitz et al. (2009) have demonstrated in vitro the oxidative stress caused in the liver by the accumulation of organic acids in this deficiency.

Pancreatitis is a potential complication in patients with organic acidemias, especially methylmalonic and isovaleric (Kahler et al. 1994) and less frequently in 3-hydroxy-3methylglutaric aciduria (Muroi et al. 2000; Wilson et al. 1984). The presence of HL protein in pancreas has been reported (MacDonald et al. 2007), but here we demonstrate that the pancreas has the highest enzymatic activity after the liver. This finding indicates that the pancreas has a high ketogenic capacity and suggests that, if ketone bodies regulate the release of insulin (Biden and Taylor 1983; Malaisse et al. 1990; Rhodes et al. 1985), some of them could be produced in the pancreas. In contrast, ketone bodies do not seem to play an important role as energy source in this organ. The finding of higher enzymatic activity in pancreas indicates that it may be more susceptible to toxic accumulation of metabolites. This hypothesis has been proposed to explain the pathogenesis of other organic acidemias of leucine catabolism (Gut et al. 

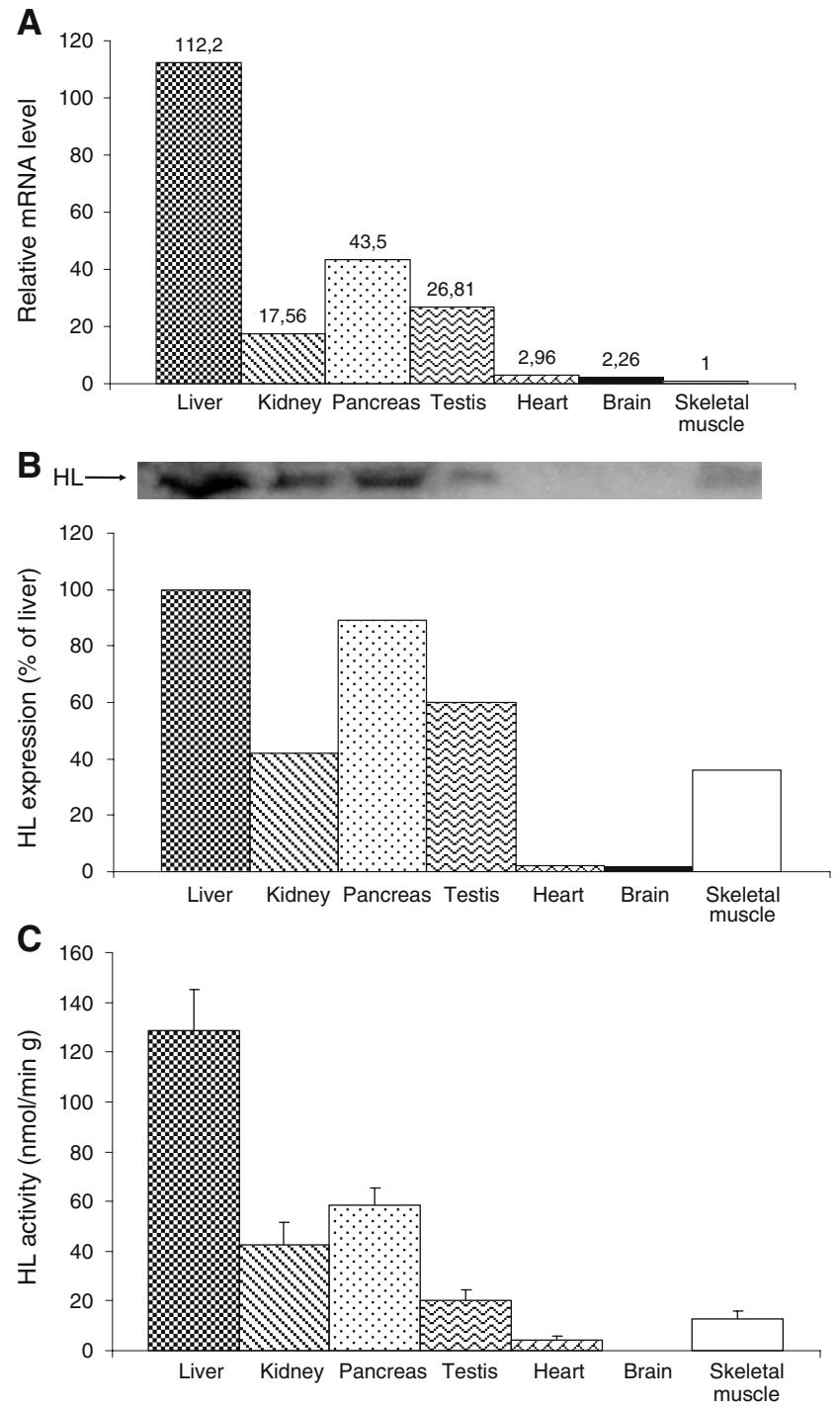

Fig 1 Comparative analysis of mRNA levels, protein expression and enzymatic activity of HMG-CoA lyase in different human tissues. a Relative levels of mRNA HL expression in human tissues were measured by the $\triangle \triangle \mathrm{CT}$ method with $G A P D H$ as control. The expression levels of mRNA HL in skeletal muscle were arbitrarily taken as the calibrator for all calculations, and all other tissues were normalized accordingly. The values given are the average of four meausures, two from each subject. b HL protein expression was measured in mitochondrial fraction from human tissues. Four tissue samples were measured, two from each subject. The image shows a representative immunoblot from HL in different tissues. c HL activity was measured in the mitochondrial fraction of human tissues spectrophotometrically. Data are presented as mean $\pm \operatorname{SEM}(n=4)$. Four tissue samples were measured, two from each subject

1995; Kahler et al. 1994). The possibility of a progressive deterioration of the pancreas, without evident clinical manifestations, led us to study the protein PAP in patients with 3-hydroxy-3-methylglutaric aciduria, in order to detect and prevent any possible pancreas damage. PAP is a more sensitive marker of pancreatitis than amylase, whose levels remain high even in absence of symptoms (Kemppainen et al. 1996). The serum studies from patients in different situations of crisis and between crises did not show pathologic elevations. However, the higher activity of HL enzyme and the severity of the complications support the need to monitor the pancreatic function in patients with HL deficiency.

This study shows that, at different levels of mRNA, protein and enzymatic activity, HL is not found in the mitochondria from human brain. The absence of lyase activity in brain mitochondria is consistent with results obtained by McGarry and Foster (1969) and Bachhawat et al. (1955) in rat but it disagrees with the results of Shah (1982). Ketogenic activity by astrocytes has been described (Auestad et al. 1991; Guzmán and Blázquez 2004), but Auestad et al. (1991) have demonstrated that acetoacetate is mainly formed in astrocytes by deacylation of acetoacetyl-CoA and not by the action of the mitochondrial HMG-CoA cycle. In conclusion, despite the difficulties of studying the human brain immediately after death to avoid protein degradation, HL activity in mitochondria from adult human brain, if present, would be minimal. We suggest that the neurological alterations, frequently associated with this deficiency, are related to hypoglycaemia and to the absence of the only alternative substrate to glucose for the brain ketone bodies. Concomitantly, our results show that the organic acids would not be produced in situ, although they could cross the bloodbrain barrier of an immature brain (Wajner et al. 2004) and cause damage.

Dilated cardiomyopathy has been described in two patients with 3-hydroxy-3-methylglutaric aciduria, one young male (Gibson et al. 1994) and one adult (Leung et al. 2009). In this last case, the authors suggest that the cardiomyopathy results from impaired ketogenesis, intracellular fatty acid accumulation and a secondary carnitine deficiency. However, we found very little HL in heart tissue, from which we conclude that it does not regulate the entry of fatty acids to the heart and thus prevent their accumulation. Therefore, our results do not support the hypothesis of local accumulation of organic acids as a cause of the cardiomyopathy. In HL deficiency, heart disease could be caused by the lack of an alternative energy substrate. The heart is a continuously active muscle which uses various energy substrates depending on their availability (Kodde et al. 2007). Although ketone bodies are not an indispensable substrate, the added L-carnitine deficiency, which is caused by the HL deficiency, could alter the transport of fatty acids to the mitochondria for oxidation and the coupling between glycolysis and glucose oxidation (Allard et al. 2006). L-carnitine supplementation has been recommended for patients with organic acidurias to allow 
the elimination of toxic acids (Chalmers et al. 1984), but it could also improve the heart function.

In HL deficiency, alterations in other organs such as kidney, testis and skeletal muscle have not been reported, although in our study the enzymatic activity in kidney was high or moderately high in testis and skeletal muscle. Surprisingly, in muscle, although the mRNA levels were very low, moderate HL activity was measured. Similar cases are reported in the literature (Lewin et al. 2001), which suggests that certain tissues may have a lower turnover of the HL protein versus an unstable mRNA. In testis, the low activity levels of HL compared with the high enzyme expression suggest that HL activity could be regulated after translation in this tissue. All these tissues use the ketone bodies as an alternative energy source, but they do not show strong dependence on them (Robinson and Williamson 1980). Moreover, they are less sensitive to the accumulation of toxic metabolites, in contrast to the brain (Wajner et al. 2004) or pancreas (Leung and Chan 2009).

The results reported here help us to understand the enzyme function and pathophysiology of the 3-hydroxy3 methylglutaric aciduria. We suggest that pancreatitis should be included as a possible complication to seek in patients with HL deficiency, especially during acute episodes. Moreover, the addition of nutritional factors, such as L-carnitine, can be essential to prevent the development of cardiomyopathy.

Acknowledgements This study was supported by grants from: Diputación General de Aragón (Ref. Grupo Consolidado B20) and (Ref. PI128/08); Spanish Ministry of Education and Science (Ref. SAF2004-06843-C03); the Ajut de Suport als Grups de Recerca de Catalunya (Ref. 2005SGR-00733). CIBER Fisiopatología de la Obesidad y Nutrición is an initiative of the Instituto de Salud Carlos III, Spain.

\section{References}

Allard ML, Jeejeebhoy KN, Sole MJ (2006) The management of conditioned nutritional requirements in heart failure. Heart Fail Rev 11:75-82

Ashmarina LI, Rusnak N, Miziorko HM et al (1994) 3-Hydroxy-3methylglutaryl-CoA lyase is present in mouse and human liver peroxisomes. J Biol Chem 269:31929-31932

Auestad N, Korsak RA, Morrow JW et al (1991) Fatty acid oxidation and ketogenesis by astrocytes in primary culture. $\mathrm{J}$ Neurochem 56:1376-1386

Bachhawat BK, Robinson WG, Coon MJ (1955) The enzymatic cleavage of beta-hydroxy-beta-methylglutaryl coenzyme A to acetoacetate and acetyl coenzyme A. J Biol Chem 216:727-736

Biden TJ, Taylor KW (1983) Effects of ketone bodies on insulin release and islet-cell metabolism in the rat. Biochem J 212:371377

Casale CH, Casals N, Pié J et al (1998) A nonsense mutation in the exon 2 of the 3-hydroxy-3-methylglutaryl coenzyme A lyase
(HL) gene producing three mature mRNAs is the main cause of 3-hydroxy-3-methylglutaric aciduria in European Mediterranean patients. Arch Biochem Biophys 349:129-137

Clinkenbeard KD, Reed WD, Mooney RA et al (1975) Intracellular localization of the 3-hydroxy-3-methylglutaryl coenzyme A cycle enzymes in liver. Separate cytoplasmic and mitochondrial 3hydroxy-3-methylglutaryl coenzyme A generating systems for cholesterogenesis and ketogenesis. J Biol Chem 250:3108-3116

Chalmers RA, Roe CR, Stacey TE et al (1984) Urinary excretion of l-carnitine and acylcarnitines by patients with disorders of organic acid metabolism: evidence for secondary insufficiency of 1-carnitine. Pediatr Res 18:1325-1328

Desjeux A, Barthet M, Barthellemy S et al (2002) Serum measurements of pancreatitis associated protein in active Crohn's disease with ileal location. Gastroenterol Clin Biol 26:23-28

Faull KF, Bolton PD, Halpern B et al (1976) The urinary organic acid profile associated with 3-hydroxy-3-methylglutaric aciduria. Clin Chim Acta 73:553-559

Gibson KM, Breuer J, Nyhan WL (1988) 3-Hydroxy-3-methylglutarylcoenzyme A lyase deficiency: review of 18 reported patients. Eur J Pediatr 148:180-186

Gibson KM, Cassidy SB, Seaver LH et al (1994) Fatal cardiomyopathy associated with 3-hydroxy-3-methylglutaryl-CoA lyase deficiency. J Inherit Metab Dis 17:291-294

Gut A, Chaloner C, Schofield D et al (1995) Evidence of toxic metabolite stress in black South Africans with chronic pancreatitis. Clin Chim Acta 236:145-153

Guzman M, Blazquez C (2004) Ketone body synthesis in the brain: possible neuroprotective effects. Prostaglandins Leukot Essent Fatty Acids 70:287-292

Kahler SG, Sherwood WG, Woolf D et al (1994) Pancreatitis in patients with organic acidemias. J Pediatr 124:239-243

Kemppainen E, Sand J, Puolakkainen P et al (1996) Pancreatitis associated protein as an early marker of acute pancreatitis. Gut 39:675-678

Kodde IF, van der Stok J, Smolenski RT et al (2007) Metabolic and genetic regulation of cardiac energy substrate preference. Comp Biochem Physiol A Mol Integr Physiol 146:26-39

Leipnitz G, Seminotti B, Fernandes CG et al (2009) Striatum is more vulnerable to oxidative damage induced by the metabolites accumulating in 3-hydroxy-3-methylglutaryl-CoA lyase deficiency as compared to liver. Int J Dev Neurosci 27:351-356

Leung PS, Chan YC (2009) Role of oxidative stress in pancreatic inflammation. Antioxid Redox Signal 11:135-165

Leung AA, Chan AK, Ezekowitz JA, et al (2009). A case of dilated cardiomyopathy associated with 3-Hydroxy-3-MethylglutarylCoenzyme A (HMG CoA) lyase deficiency. Case Report Med. 183125.

Lewin TM, Granger DA, Kim JH et al (2001) Regulation of mitochondrial sn-glycerol-3-phosphate acyltransferase activity: response to feeding status is unique in various rat tissues and is discordant with protein expression. Arch Biochem Biophys 396:119-127

MacDonald MJ, Smith AD 3rd, Hasan NM et al (2007) Feasibility of pathways for transfer of acyl groups from mitochondria to the cytosol to form short chain acyl-CoAs in the pancreatic beta cell. J Biol Chem 282:30596-30606

Malaisse WJ, Lebrun P, Rasschaert J et al (1990) Ketone bodies and islet function: $86 \mathrm{Rb}$ handling and metabolic data. Am J Physiol 259:E123-E130

McGarry JD, Foster DW (1969) Ketogenesis and cholesterol synthesis in normal and neoplastic tissues of the rat. J Biol Chem 244:4251-4256

Menao S, López-Viñas E, Mir C et al (2009) Ten novel HMGCL mutations in 24 patients of different origin with 3-hydroxy-3methyl-glutaric aciduria. Hum Mutat 30:520-529 
Mitchell GA, Kassovska-Bratinova S, Boukaftane Y et al (1995) Medical aspects of ketone body metabolism. Clin Invest Med 18:193-216

Muroi J, Yorifuji T, Uematsu A et al (2000) Cerebral infarction and pancreatitis: possible complications of patients with 3-hydroxy-3methylglutaryl-CoA lyase deficiency. J Inherit Metab Dis 23:636-637

Robinson AM, Williamson DH (1980) Physiological roles of ketone bodies as substrates and signals in mammalian tissues. Physiol Rev 60:143-187

Rhodes CJ, Campbell IL, Szopa TM et al (1985) Effects of glucose and D-3-hydroxybutyrate on human pancreatic islet cell function. Clin Sci 68:567-572

Schutgens RB, Heymans H, Ketel A et al (1979) Lethal hypoglycemia in a child with a deficiency of 3-hydroxy-3-methylglutarylcoenzyme A lyase. J Pediatr 94:89-91

Shah SN (1982) Cytosolic 3-hydroxy-3-methyl glutaryl coenzyme a synthase in rat brain: properties and developmental change. Neurochem Res 7:1359-1366

Urganci N, Arapoglu M, Evruke M et al (2001) A rare cause of hepatomegaly: 3-hydroxy-3-methylglutaryl coenzyme-a lyase deficiency. J Pediatr Gastroenterol Nutr 33:339-341

Wajner M, Latini A, Wyse AT et al (2004) The role of oxidative damage in the neuropathology of organic acidurias: insights from animal studies. J Inherit Metab Dis 27:427-448
Wanders RJ, Schutgens RB, Zoeters PH (1988) 3-Hydroxy-3methylglutaryl-CoA lyase in human skin fibroblasts: study of its properties and deficient activity in 3-hydroxy-3-methylglutaric aciduria patients using a simple spectrophotometric method. Clin Chim Acta 171:95-101

Wilson WG, Cass MB, Sovik O et al (1984) A child with acute pancreatitis and recurrent hypoglycemia due to 3-hydroxy-3methylglutaryl-CoA lyase deficiency. Eur J Pediatr 142:289 291

Wysocki SJ, Hahnel R (1976a) 3-Hydroxy-3-methylglutaric aciduria: 3-hydroxy-3-methylglutaryl-coenzyme A lyase levels in leucocytes. Clin Chim Acta 73:373-375

Wysocki SJ, Hahnel R (1976b) 3-Hydroxy-3-methylglutaric aciduria: deficiency of 3-hydroxy-3-methylglutaryl coenzyme A lyase. Clin Chim Acta 71:349-351

Wysocki SJ, Hahnel R (1986) 3-Hydroxy-3-methylglutaryl-coenzyme a lyase deficiency: a review. J Inherit Metab Dis 9:225-233

Zafeiriou DI, Vargiami E, Mayapetek E et al (2007) 3-Hydroxy-3methylglutaryl coenzyme a lyase deficiency with reversible white matter changes after treatment. Pediatr Neurol 37:47-50

Zoghbi HY, Spence JE, Beaudet AL et al (1986) Atypical presentation and neuropathological studies in 3-hydroxy-3-methylglutarylCoA lyase deficiency. Ann Neurol 20:367-369 